\title{
Melt-Blown and Electrospun Drug-Loaded Polymer Fiber Mats for Dissolution Enhancement: A Comparative Study
}

\author{
ATTILA BALOGH, ${ }^{1}$ BALÁZS FARKAS, ${ }^{1}$ KORNÉl FARAGÓ, ${ }^{1}$ ATTILA FARKAS, ${ }^{1}$ ISTVÁN WAGNER, ${ }^{1}$ IVO VAN ASSCHE, ${ }^{2}$ \\ GEERT VERRECK, ${ }^{2}$ ZSOMBOR K. NAGY, ${ }^{1}$ GYÖRGY MAROSI ${ }^{1}$ \\ ${ }^{1}$ Budapest University of Technology and Economics, Organic Chemistry and Technology Department, Budapest $\mathrm{H}-1111, \mathrm{Hungary}$ \\ ${ }^{2}$ Chemical and Pharmaceutical Development, Johnson \& Johnson Pharmaceutical Research and Development, Janssen Pharmaceutica, \\ Beerse B-2340, Belgium
}

Received 20 November 2014; revised 29 January 2015; accepted 30 January 2015

Published online in Wiley Online Library (wileyonlinelibrary.com). DOI 10.1002/jps.24399

\begin{abstract}
Melt blowing (MB) was investigated to prepare a fast dissolving fibrous drug-loaded solid dispersion and compared with solventbased electrospinning (SES) and melt electrospinning (MES). As a conventional solvent-free technique coupled with melt extrusion and using a high-speed gas stream, MB can provide high-quality micro- and nanofibers at industrial throughput levels. Carvedilol, a weak-base model drug with poor water solubility, was processed using a common composition optimized for the fiber spinning and blowing methods based on a hydrophilic vinylpyrrolidone-vinyl acetate copolymer (PVPVA64) and PEG 3000 plasticizer. Scanning electron microscopy combined with fiber diameter analysis showed diameter distributions characteristic to each prepared fibrous fabrics (the mean value increased toward $\mathrm{SES}<\mathrm{MB}<\mathrm{MES}$ ). Differential scanning calorimetry and X-ray diffraction studies revealed that the incorporated drug was in amorphous form regardless the preparation method. The HPLC studies demonstrated that all of the materials produced by the different techniques passed the regulatory purity requirements. The fibers exhibited ultrafast drug release tested under neutral $\mathrm{pH}$ conditions; the melt-blown sample dissolved within 2 min owing to its large specific surface area. The presented results confirm the applicability of MB as a novel formulation technique for polymer-based drug delivery systems. (C) 2015 Wiley Periodicals, Inc. and the American Pharmacists Association J Pharm Sci
\end{abstract}

Keywords: electrospinning; melt electrospinning; melt blowing; extrusion; oral drug delivery; solid dispersion; enhanced dissolution rate; continuous pharmaceutical manufacturing; viscosity; HPLC

\section{INTRODUCTION}

In recent years, solvent-based electrospinning (SES) has been found to be a new and effective formulation technique to produce amorphous solid dispersions for controlled delivery of the active pharmaceutical ingredients (APIs). ${ }^{1}$ SES involves a high-voltage electrostatic field used to draw fibers reaching submicronic diameters from a viscous solution leading to an amorphous solid solution of the API incorporated in the polymeric matrix. Among the drug-loaded electrospun fibers presented so far, ${ }^{2-7}$ applications for gastrointestinal delivery with enhanced drug release rates are the most promising as there is an increasing number of drugs with poor water solubility, ${ }^{8,9}$ that is, with insufficient bioavailability at peroral administration (which is the most popular route because of the simplicity of taking and good patient compliance). ${ }^{10,11}$ The huge surface area of the nanofibers according to the Noyes-Whitney equation ${ }^{12}$ as well as the increased solubility of the amorphous drug formed during the uniquely fast $(t<0.1 \mathrm{~s})^{13}$ SES process both result in improved dissolution of the poorly soluble drug. Moreover, SES can be conducted at room temperature in a gentle way with low power consumption avoiding problems related to other techniques to produce solid dispersions. In turn, freeze-drying is an energy-intensive technology with long processing time periods,

Correspondence to: Zsombor Nagy (Telephone: +36-1-4631424; Fax: +36-1 4633648; E-mail: zsknagy@oct.bme.hu)

Journal of Pharmaceutical Sciences

(C) 2015 Wiley Periodicals, Inc. and the American Pharmacists Association whereas spray drying can produce only larger micronic particles from a more diluted solution using a heated air stream. However, the use of organic solvents to conduct solvent-based techniques also involves the risk of explosion (i.e., explosion proof design is required), the need of tail gas cleaning and the probability of undesired toxic solvent residue in the product.

The solvent-free "green" variant of electrospinning, melt electrospinning (MES), is also capable to produce fibers from a polymer melt obtaining large surface area with fast drug release rates. ${ }^{14}$ In this case, the preparation of the melt and the amorphization of the API occur preferably during melt extrusion, a widely investigated continuous tool having been applied for commercialized pharmaceutical products as well. ${ }^{15-21}$ The integration of MES into melt-extrusion technology line can be a viable continuous tool to produce solid dispersions with high surface area in one single step.

Despite the advantageous properties, both SES and MES have their own limitations. Although there have been attempts for process scale-up, both for $\mathrm{MES}^{22,23}$ and particularly for SES applying a needleless (free surface) configuration, ${ }^{24-26}$ the achievable productivity is moderate compared with other fiber production techniques, ${ }^{27}$ and the use of volatile solvents seems to complicate the intensification because of the undesired drying of the free solution surface. Although MES can eliminate all the technological problems related to solvents mentioned above, only fibers of several tens of micrometers are achievable owing to the high-melt viscosity. ${ }^{28}$

A conventional fabrication method of micro- and nanofibers is melt blowing (MB) where a polymer melt is extruded through 
small nozzles surrounded by high-speed blowing gas. ${ }^{29}$ The first research on $\mathrm{MB}$ was a naval attempt to produce fine filtration materials for radiation measurements on drone aircrafts in the 1950s. ${ }^{30}$ Later on, Exxon Corporation developed an industrial process based on the MB principle with high-throughput levels. ${ }^{31} \mathrm{MB}$ appears to be a promising technique to prepare drug-loaded fibers combining the advantages of SES, MES, and thus, melt extrusion accompanied with excellent productivity. However, MB has not been used yet for preparing drug delivery systems.

In the work outlined in this paper, a comparison has been made between the referred three fiber formation techniques, SES, MES, and MB with the same composition to improve the dissolution characteristics of the poorly water-soluble model drug carvedilol (CAR). As melt extrusion served the input for MES and MB, it was also involved as a reference method. According to our previous reports, drug-loaded MES fibers can be produced using a polymer (Eudragit ${ }^{\circledR}$ E) soluble at acidic pH. ${ }^{14,32}$ Now, our aim was selecting a polymeric matrix that ensures enhanced dissolution at neutral $\mathrm{pH}$ as well, in which, however, the solubility of the weak-base CAR is lower than in acidic media. ${ }^{33}$ Developing such a formulation is of a great therapeutic importance considering that the normally acidic gastric $\mathrm{pH}$ can be shifted toward neutral values because of various factors, ${ }^{34}$ for instance, the ingested food, ${ }^{35}$ disorders (e.g., AIDS), ${ }^{36}$ medication (e.g., antacids, proton-pump inhibitors, $\mathrm{H}_{2}$ receptor antagonists), ${ }^{37,38}$ or the residence time in the stomach can be very short (even $15 \mathrm{~s}$ ) when the solid dosage form is taken into an empty stomach. ${ }^{39}$ After finding and processing the appropriate composition, besides characterization of the morphology, the physical state of CAR and the dissolution kinetics of the samples, impurity measurements were also performed to assess the degrading effect of the different methods on the API.

\section{MATERIALS AND METHODS}

\section{Materials}

Carvedilol (free base; Fig. 1a) from Sigma-Aldrich (Budapest, Hungary) with purity $\geq 99 \%$ was used as API. PVPVA64 (Kollidon ${ }^{\circledR}$ VA 64; Fig. 1b) was kindly provided by BASF (Ludwigshafen, Germany), which is an N-vinylpyrrolidone-vinyl acetate amorphous copolymer (1.2:1 molar ratio, i.e., 6:4 mass ra-

a<smiles>COc1ccccc1OCCNCC(O)COc1cccc2[nH]c3ccccc3c12</smiles>

b<smiles>CC(=O)OC(C)CC(C)(C)[C@H](C)CC(C)(C)C(C)C</smiles>

Figure 1. The structure of (a) CAR and (b) PVPVA64. tio), with an average molecular weight of 45-70 kDa. Polyethylene glycols (PEGs) (average molecular weights: 1500 and 3000 $\mathrm{Da}$, respectively) were used as additives from Sigma-Aldrich.

\section{Solvent-Based Electrospinning}

The solvent-based electrostatic spinner used for the experiments was equipped with NT-35 high-voltage DC supply (MA2000; Unitronik Ltd., Nagykanizsa, Hungary). The electrical potential applied on the spinneret electrode was $25 \mathrm{kV}$. A grounded aluminum plate covered with aluminum foil was used as collector. The distance of the spinneret and the collector was $20 \mathrm{~cm}$ and the experiments were performed at room temperature. Fibers could be readily formed from an ethanolic PVPVA64 solution; however, addition of dichloromethane (DCM) was required to dissolve PEGs and dimethylformamide (DMF) was also introduced as a fiber thinning agent. Thus, $2.5 \mathrm{~g}$ PVPVA64 was dissolved in $4 \mathrm{~mL}$ of an ethanol-DCM-DMF (5:1:4) ternary mixture while stirred without heating; the PEG and the API were added subsequently. The solution was dosed by a SEP-10S Plus type syringe pump (Aitecs, Vilnius, Lithuania) with a dosing rate of $4 \mathrm{~mL} / \mathrm{h}$.

\section{Melt Extrusion}

Extrudates containing CAR were prepared by HAAKE MiniLab micro compounder (Thermo-Haake, Karlsruhe, Germany). A certain amount of PVPVA64 and CAR (10\%) was mixed well with and without PEG and the mixture was introduced into the hopper of the miniextruder. The rotation speed was fixed at $100 \mathrm{rpm}$; the temperature was $120^{\circ} \mathrm{C}$ without $\mathrm{PEG}$ and $110^{\circ} \mathrm{C}$ when PEG was applied. The obtained extrudates were ground in a mortar and sieved (size: $400 \mu \mathrm{m}$ ).

\section{Melt Electrospinning}

The solid dispersion prepared by melt extrusion was fed into MES equipment, which was designed and built at Department of Organic Chemistry, Budapest University of Technology and Economics (Budapest, Hungary). The MES equipment (Fig. 2a) has two temperature-controlled zones and a programmable feeder. The applied feeding rate was $1 \mathrm{~mL} / \mathrm{h}$ and the temperature of the feeding unit $\left(T_{\mathrm{B}}\right)$ was similar to that of melt extrusion. The spinneret temperature $\left(T_{\mathrm{A}}\right)$ determination was supported by oscillatory rheology measurements (see section "Results and Discussion"). The distance of the spinneret and the collector was $10 \mathrm{~cm}$. The stainless steel metal syringe is

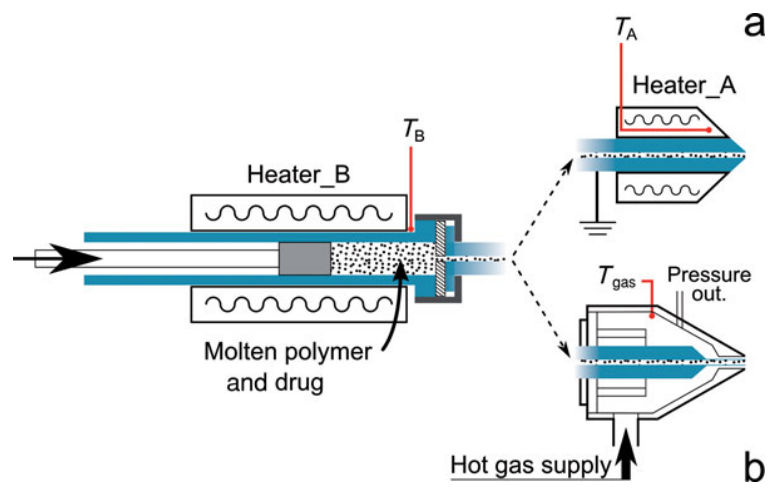

Figure 2. The schematic drawing of the two-zone-heated stainless steel metal syringe coupled (a) with a MES or (b) a MB spinneret. 
Table 1. Composition, Production Parameters, Diameter Analysis, and Specific Surface Area of the Samples

\begin{tabular}{|c|c|c|c|c|c|}
\hline \multicolumn{2}{|l|}{ Production Process } & SES & MES & MB & Extrusion \\
\hline \multicolumn{2}{|l|}{ CAR (mass, \%) } & 10 & 10 & 10 & 10 \\
\hline \multicolumn{2}{|l|}{ PVPVA64 (mass, \%) } & 75 & 75 & 75 & 75 \\
\hline \multicolumn{2}{|l|}{ PEG 3000 (mass, \%) } & 15 & 15 & 15 & 15 \\
\hline \multicolumn{2}{|l|}{ Peak temperature $\left({ }^{\circ} \mathrm{C}\right)$} & 25 & 145 & 145 & 110 \\
\hline \multicolumn{2}{|l|}{ Flow rate $(\mathrm{mL} / \mathrm{h})$} & 4 & 1 & 1 & 80 \\
\hline \multicolumn{2}{|c|}{ Output on laboratory scale (g/h) } & 1.8 & 1.2 & 1.2 & 96 \\
\hline \multicolumn{2}{|c|}{ Mean fiber or particle diameter $(\mu \mathrm{m}, \pm \mathrm{SD})$} & $1.8 \pm 0.3$ & $45.9 \pm 11.3$ & $9.4 \pm 2.2$ & $300^{a}$ \\
\hline \multirow[t]{3}{*}{ Lognormal distribution fit } & $\mu$ & 0.593 & 3.797 & 2.219 & - \\
\hline & $\sigma$ & 0.179 & 0.250 & 0.229 & - \\
\hline & $R^{2}$ & 0.9665 & 0.9129 & 0.9488 & - \\
\hline \multicolumn{2}{|l|}{ Specific surface area $\left(\mathrm{m}^{2} / \mathrm{g}\right)^{b}$} & 1.81 & 0.07 & 0.35 & 0.017 \\
\hline
\end{tabular}

${ }^{a}$ Estimated based on SEM images.

${ }^{b}$ Calculated from mean fiber or spherical particle size.

easy to clean; the spinneret part is dismountable and the capillary tube can be replaced for a new experiment, if it is needed.

\section{Melt Blowing}

The MB experiments were performed similarly to MES, the feeding unit was the same, which was equipped with a newly designed MB head (Fig. 2b), and an external gas-heater unit and further devices were attached to maintain and monitor the gas supply of the blowing process. Thus, the feeding temperature $\left(T_{\mathrm{B}}\right)$ was similar to that of melt extrusion, and the same nozzle temperature (i.e., blowing gas temperature, $T_{\mathrm{GAS}}$ ) and polymer feeding rate were applied as during MES (Table 1). The airflow was supplied by an oil-free membrane compressor (SF 1 FF; Atlas Copco, Stockholm, Sweden) and was controlled by manual feedback on the MB head pressure that was maintained at 1.6 bar. Although the volumetric flow of the input cold air stream could be determined using a rotameter $(12 \mathrm{~L} / \mathrm{min})$, the air speed through the MB coaxial capillary tube was calculated based on the measured static pressure and temperature in the chamber because the flow is considered to be compressible with Mach numbers (the ratio of the actual and sonic velocity) greater than $0.3 .{ }^{40}$ Assuming an isentropic expansion of an ideal gas, the measured 1.6 bar absolute pressure in the MB head resulted in an air speed of $325 \mathrm{~m} / \mathrm{s}$ (Mach number of 0.85 ) at the exit of the orifice. For the collection of the fibers, a basket with vents was placed $30 \mathrm{~cm}$ away from the MB head. As the basic structure of the MB nozzle was similar to that of the MES nozzle, the cleaning and replacement of the internal needle could be easily performed.

\section{Scanning Electron Microscopy and Fiber Diameter Analysis}

Morphology of the samples was investigated by a JEOL 6380LVa (JEOL, Tokyo, Japan) type scanning electron microscope. Each specimen was fixed by conductive double-sided carbon adhesive tape and sputter-coated with gold prior to the examination. Applied accelerating voltage and working distance were $15-30 \mathrm{kV}$ and $10 \mathrm{~mm}$, respectively. A randomized fiber diameter determination method was developed based on scanning electron microscopy (SEM) imaging. Ten images were taken of each prepared fiber population, then, on each image, random points were marked by a short program written in $\mathrm{C}++$ (Visual Studio Express 2008; Microsoft, Redmond, Washington). At these points, the diameters (where possible; $n=10$ for each image, $n=100$ for each sample) and also the scale bars of the SEM images for reference were drawn manually using a vector graphics editor (Inkscape). Another $\mathrm{C}++$ program was written and used to evaluate the drawn diameters quickly and convert into a text file. Lognormal distribution fitting was calculated using Statistica v10 (StatSoft, Tulsa, Oklahoma).

\section{Differential Scanning Calorimetry}

Differential scanning calorimetry (DSC) measurements were carried out using a TA Instruments Q2000 DSC apparatus (New Castle, Delaware) (sample weight: $\sim 2-3 \mathrm{mg}$, closed aluminum pan, $50 \mathrm{~mL} / \mathrm{min}$ nitrogen purge gas). The temperature program consisted of an isothermal period, which lasted for $1 \mathrm{~min}$ at $-30^{\circ} \mathrm{C}$, with subsequent linear heating from $-30^{\circ} \mathrm{C}$ to $200^{\circ} \mathrm{C}$ at the rate of $10^{\circ} \mathrm{C} / \mathrm{min}$. Purified indium standard was used to calibrate the instrument.

\section{X-ray Diffraction}

Powder X-ray diffraction (XRD) patterns were recorded by a PANanalytical X'pert Pro MDP X-ray diffractometer (Almelo, The Netherlands) using $\mathrm{Cu}-\mathrm{K} \alpha$ radiation (1.542 $\AA$ ) and Ni filter. The applied voltage was $40 \mathrm{kV}$, whereas the current was $30 \mathrm{~mA}$. The untreated materials, physical mixture (mixed in a mortar by a pestle), fibers, and extrudate were analyzed for angles $2 \theta$ between $4^{\circ}$ and $42^{\circ}$.

\section{Rheology}

Viscosity measurements as a function of temperature were carried out of the extruded samples using an AR 2000 Rotational Rheometer (TA Instruments) in oscillating mode with a parallel plate configuration. The upper moved portion was a $40-\mathrm{mm}$ diameter steel plate and the lower portion was a Teflon-coated Peltier plate. The extruded samples were placed on the preheated Peltier plate and melted. The upper plate was then lowered to the gap of $500 \mu \mathrm{m}$. The controlled variable was the oscillating torque, oscillatory tests were carried out at 1000 $\mu \mathrm{Nm}$ torque and $1 \mathrm{~Hz}$ frequency, and dynamic stress sweep tests confirmed that the measurements were made in the linear viscoelastic region. The temperature was ramped down from $180^{\circ} \mathrm{C}$ to $100^{\circ} \mathrm{C}$ with a linear rate of $5^{\circ} \mathrm{C} / \mathrm{min}$. Frequency sweep tests were carried out under the same circumstances with selected extrudates at an appropriate melting temperature between 0.01 and $100 \mathrm{~Hz}$ oscillation frequency. The tests were carried out in triplicate. 


\section{HPLC Studies}

Chemical stability of CAR during the formulation process was determined through analyzing the decomposition byproducts using RP-HPLC (Agilent 1200 series LC System; Santa Clara, California). A gradient elution of $0.1 \mathrm{M}$ phosphoric acid and acetonitrile was performed at a flow rate of $1.0 \mathrm{~mL} / \mathrm{min}$ and $25^{\circ} \mathrm{C}$ started at $25 \%$ acetonitrile, increased linearly to $60 \%$ over 40 min and maintained for $5 \mathrm{~min}$, then returned to the initial composition over $10 \mathrm{~min}$. The UV detection wavelength was set to $285 \mathrm{~nm}$. The pure API, the extruded, and fibrous samples were dissolved in the initial mobile phase of gradient elution obtaining an $1 \mathrm{mg} / \mathrm{mL}$ solution of CAR; $20 \mu \mathrm{L}$ of this stock solution were injected onto the column [Phenomenex Luna C18 column ( $5 \mu \mathrm{m} ; 150 \times 4.6 \mathrm{~mm})$; Torrance, California]. The amount of the degradation products was determined based on the peak areas. The absorption coefficients of the byproducts are higher than that of the pure CAR, ${ }^{41}$ which precludes the underestimation of the concentration of the degradation products. The chromatography tests were performed in triplicate.

\section{In Vitro Dissolution Measurement}

The dissolution studies were performed using a Pharmatest PTWS 600 dissolution tester [USP II apparatus (paddle); Hainburg, Germany]. Samples equivalent to $12.5 \mathrm{mg}$ of CAR were added directly in the dissolution vessel containing $900 \mathrm{~mL} \mathrm{pH}$ $6.8100 \mathrm{mM}$ phosphate buffer prepared according to USP. Fibrous samples were used for dissolution tests as spun. The temperature was maintained at $37 \pm 0.5^{\circ} \mathrm{C}$ and stirred at $100 \mathrm{rpm}$. Samples $(5 \mathrm{~mL})$ were filtered $(0.45 \mu \mathrm{m}$ membrane $)$ and collected periodically, and the concentration of CAR was determined by UV spectrophotometry at $242 \mathrm{~nm}$ (Agilent $8453 \mathrm{UV}-\mathrm{Vis}$ spectrophotometer; Palo Alto, California). Percentage of dissolution was readily calculated according to the calibration curves of CAR in pH 6.8 phosphate buffer because of the lack of absorption peaks of the applied excipients in this range.

\section{RESULTS AND DISCUSSION}

\section{Adjustment of the Composition}

Among the pharmaceutically applicable polymers, which are well soluble at acidic as well as neutral $\mathrm{pH}$ values, there are a limited number of compounds suitable for fiber formation both from solution and melt. In order to compare the three fiber formation processes (MB, MES, and SES), a common composition was required. However, the main bottleneck of finding an appropriate polymer was found to be the high melt viscosity that prevents drawing a fibrous material exploiting the attraction force of the electrostatic field. The viscosity range required for MES is $100-200$ Pa s or less. ${ }^{28}$

Oscillatory viscosimetry was applied to determine the effect of the composition on the melt properties (Fig. 3a). The selected PVPVA64 polymer of high water solubility and glass transition temperature of around $107^{\circ} \mathrm{C}^{42}$ has a high melt viscosity in unmodified form (even at extremely elevated temperatures), which means a challenge for fiber formation. The incorporation of $10 \%$ of the model drug (CAR) into the polymer matrix resulted in advantageous drop of viscosity; however, it was not enough for reaching the desired range for MES (i.e., below 100$200 \mathrm{~Pa} \mathrm{~s}$ ) at a satisfactorily low temperature. One way to overcome this difficulty is to further increase the mass percentage
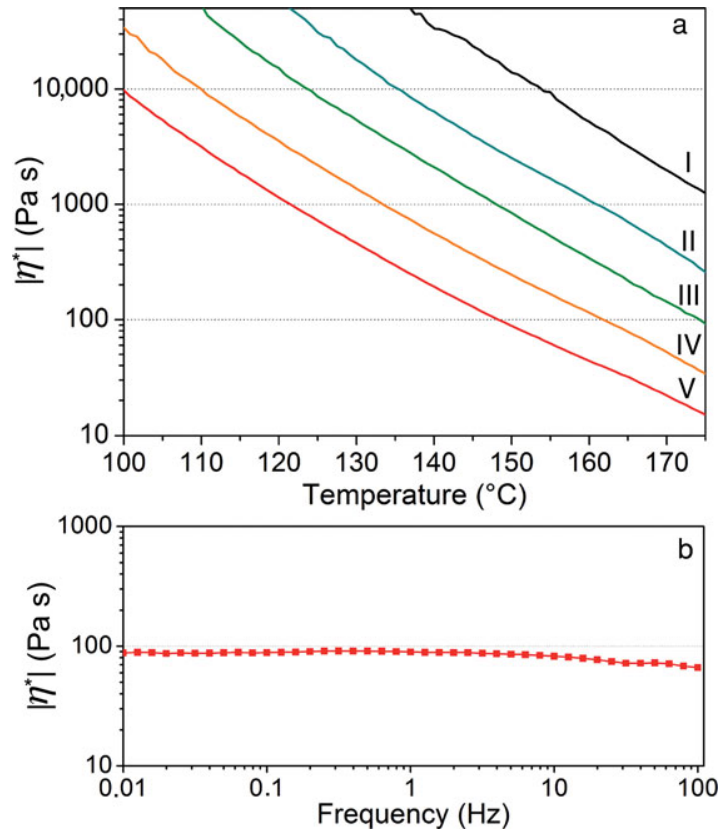

Figure 3. (a) Complex viscosity of (I) pure PVPVA64 and PVPVA64based solid dispersions with (II) $10 \%$ CAR or $10 \%$ CAR and (III) $5 \%$, (IV) $10 \%$, and (V) $15 \%$ PEG 3000 , respectively, as a function of temperature $(\omega=1 \mathrm{~Hz})$. (b) Complex viscosity of PVPVA64+10\%CAR+15\%PEG3000 blend at $145^{\circ} \mathrm{C}$ as a function of increasing dynamic frequency.

of the API. Nevertheless, higher loadings of the drug may have a well-known hydrophobization side effect that can unfavorably lower the dissolution rates. ${ }^{43}$ According to our earlier experiences, even a composition containing 20\% CAR using a more plastic carrier (Eudragit ${ }^{\circledR}$ E) could have been melt electrospun at a relatively high temperature. ${ }^{14}$ Thus, instead of increasing the API concentration, a hydrophilic plasticizer was introduced into the PVPVA64-CAR dispersion in order to lower the process temperature. Low-molecular-weight semicrystalline PEGs are an efficient plasticizing agent, whereas the handling of the product and drug release is not influenced negatively. Concentration levels of $5 \%, 10 \%$, and $15 \%$ of PEG 3000 were evaluated in regard of the dependence of melt viscosity over temperature. The logarithmic viscosity curves were closely straight and parallel indicating the good mutual miscibility of the components in melt at elevated temperatures, which was also evidenced by the yellowish transparent appearance of the prepared binary and ternary blends using the melt-extrusion technique. Although 5\% and 10\% of PEG could not provide the desired plasticizing efficiency, the PVPVA64+10\%CAR+15\%PEG3000 composition showed low-enough viscosity for MES at an acceptable temperature of $T_{\mathrm{A}}=145^{\circ} \mathrm{C}$ (Fig. 3a, curve $\mathrm{V}$ ).

It must be noted that blends composed with lower molecular weight PEGs (e.g., the semisolid PEG 1500) resulted in a sticky and hygroscopic material, whereas the more crystalline PEG 3000 has eliminated those problems.

\section{Fiber Morphology and Diameter Analysis}

In good accordance with the oscillatory viscosity measurements, the optimized blend containing PVPVA64 as a carrier and fiber former, $10 \%$ API and 15\% PEG as plasticizer, was successfully melt electrospun with diameters of $30-60 \mu \mathrm{m}$ at the predicted $145^{\circ} \mathrm{C}$ nozzle temperature (Fig. 4a). However, the 


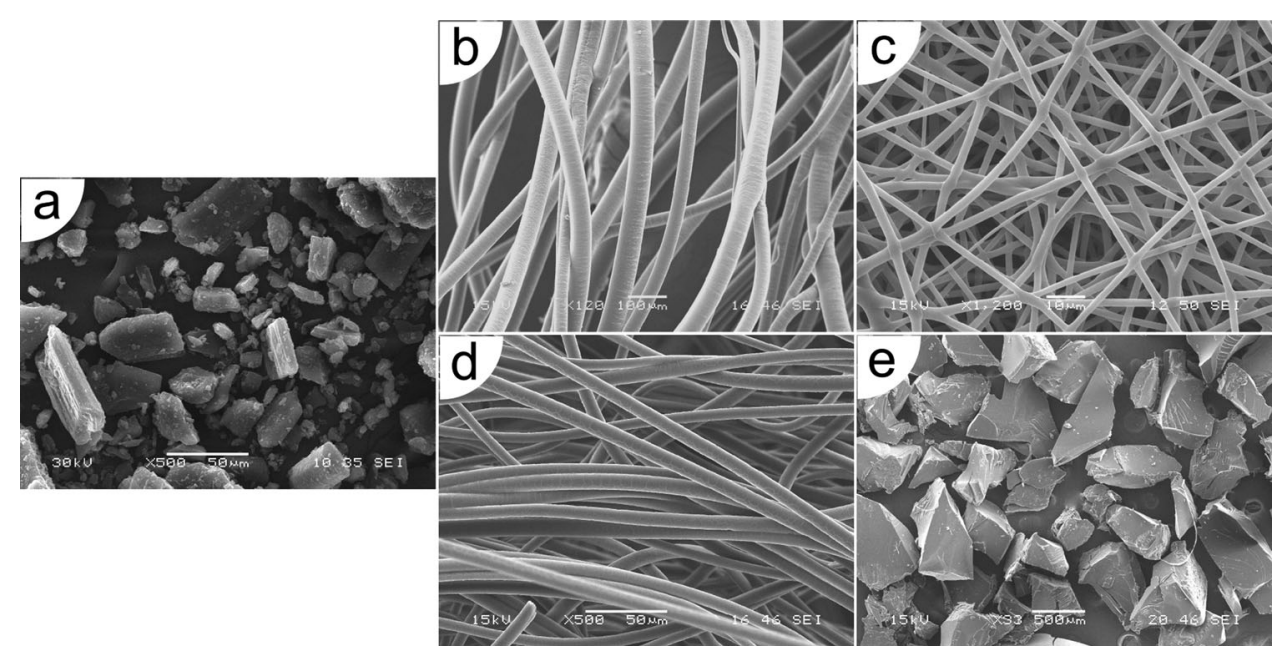

Figure 4. Scanning electron microscopic images of (a) crystalline CAR and PVPVA64-based (b) melt electrospun fibers, (c) solvent-based electrospun fibers, (d) melt-blown fibers, and (e) ground extrudate containing similarly 10\% CAR and $15 \%$ PEG 3000.

MES experiments showed that the observable vigorous movement of the molten jet (which contributes to fiber thinning ${ }^{44}$ ) slowed down when the nozzle was slightly colder $\left(5^{\circ} \mathrm{C}\right)$ as the viscosity depended on the temperature quite sensitively.

The SES could also produce a good quality mat composing from the identical polymer-drug-plasticizer mixture. Though the presence of PEG 3000 necessitated additional optimization on the polymer concentration in the solution and the organic cosolvent itself (see section "Materials and Methods"), beadfree fibers were obtained with diameters of around $2 \mu \mathrm{m}$, but submicronic fibers were also observable (Fig. 4b).

The morphology of the drug-loaded melt-blown sample is presented in Figure 4c. The MB experiments were conducted under the same circumstances (i.e., $1 \mathrm{~mL} / \mathrm{h}, 145^{\circ} \mathrm{C}$ spinneret or air stream temperature) as MES except that not an electrostatic field but a high-speed air stream was used to form the fibers. The calculated air velocity at the exit of the orifice was $325 \mathrm{~m} / \mathrm{s}, 0.85$-fold of the actual sonic velocity. Continuous fiber formation was observable during the blowing process using PVPVA64 as a matrix. The diameters of the MB fibers were around 5-15 $\mu \mathrm{m}$ implying that the blowing force considerably exceeds the impact of the electrostatic field used at MES under the same circumstances. Although the feeding rate of the MB experiments was slow, an industrial MB die can have a satisfying throughput maintaining excellent fiber morphology.

It is known that electrospinning techniques ${ }^{45}$ as well as $\mathrm{MB}^{46}$ produce fibers with lognormal diameter distribution. Fitting a lognormal probability distribution on the measured diameters yields the location parameter $(\mu)$ and the scale parameter $(\sigma)$ that can be used to compare the predicted populations on a logarithmically scaled abscissa obtaining symmetrical bell curves (i.e., apparently normal distributions).

As it can be seen in Figure 5, the diameter distributions of the fibers produced by the three different techniques are very well separated as either the initial viscosity or the type of the drawing force distinctly differ. Electrospinning from solutions can produce submicronic fibers because of the lower viscosity and intense movement of the jet-promoting elongation of polymer chains, whereas when electrospinning from melts with one order of magnitude larger viscosity, fibers usually in excess of $10 \mu \mathrm{m}$ are achievable. In contrast to MES, MB is capable of producing fibers even with average diameters of 1-2 $\mu \mathrm{m}$, but the submicronic range can also be reached. ${ }^{31,46}$ The force of the high-velocity air exerted on the surface of the polymer melt offers greater stretching compared with the high-voltage electrostatic field. Further reason of the fivefold difference in average fiber diameter between the drug-loaded MES and MB samples could be a decreased viscosity value at higher shear rates (thixotropy). The dynamic frequency sweep tests showed negligible deflection at high shear rates in Figure $3 \mathrm{~b}$; however, the shear rate occurring during MB can exceed several orders of magnitude the measuring range of a rheometer. ${ }^{31}$ The width of the fitted peaks of diameter distribution varies slightly on the logarithmic scale: SES fibers have the narrowest and MES fibers have the widest distribution. The wider relative deviations of the MES diameters may be because of the aforementioned sensitive dependence of the viscosity on the temperature, the effect of which could not be completely eliminated by the moderate electrostatic force.

From a pharmaceutical point of view, fibers with smaller diameters exhibit larger specific surface area that can be advantageous for dissolution enhancement according to the NoyesWhitney equation. Furthermore, the differences in the basic principles between the fiber formation techniques leading to significant variation in mean diameters may also have a notable effect on the physicochemical properties of the solid dispersions (see Table 1 for further details about the samples).

\section{Differential Scanning Calorimetry}

In order to investigate the physical state of the API and the excipients, DSC measurements were performed (Fig. 6).

The physical mixtures of PVPVA64 and 5\% CAR as well as PEG 3000 and CAR (5:1 mass ratio) served as references; the melting peak of the crystalline $\mathrm{CAR}$ at $117^{\circ} \mathrm{C}$ was clearly detectable. The weak change in the specific heat belonging to the glass transition of the pure PVPVA64 was barely observable next to the wide endothermic peak of water loss; PVPVA64 has a glass transition temperature $\left(T_{\mathrm{g}}\right)$ of $107^{\circ} \mathrm{C} .^{42}$ The melting point of PEG 3000 could easily be measured at $60^{\circ} \mathrm{C}$; crystalline PEGs have particularly high enthalpy of fusion (almost two-thirds of that of water). ${ }^{47}$ 

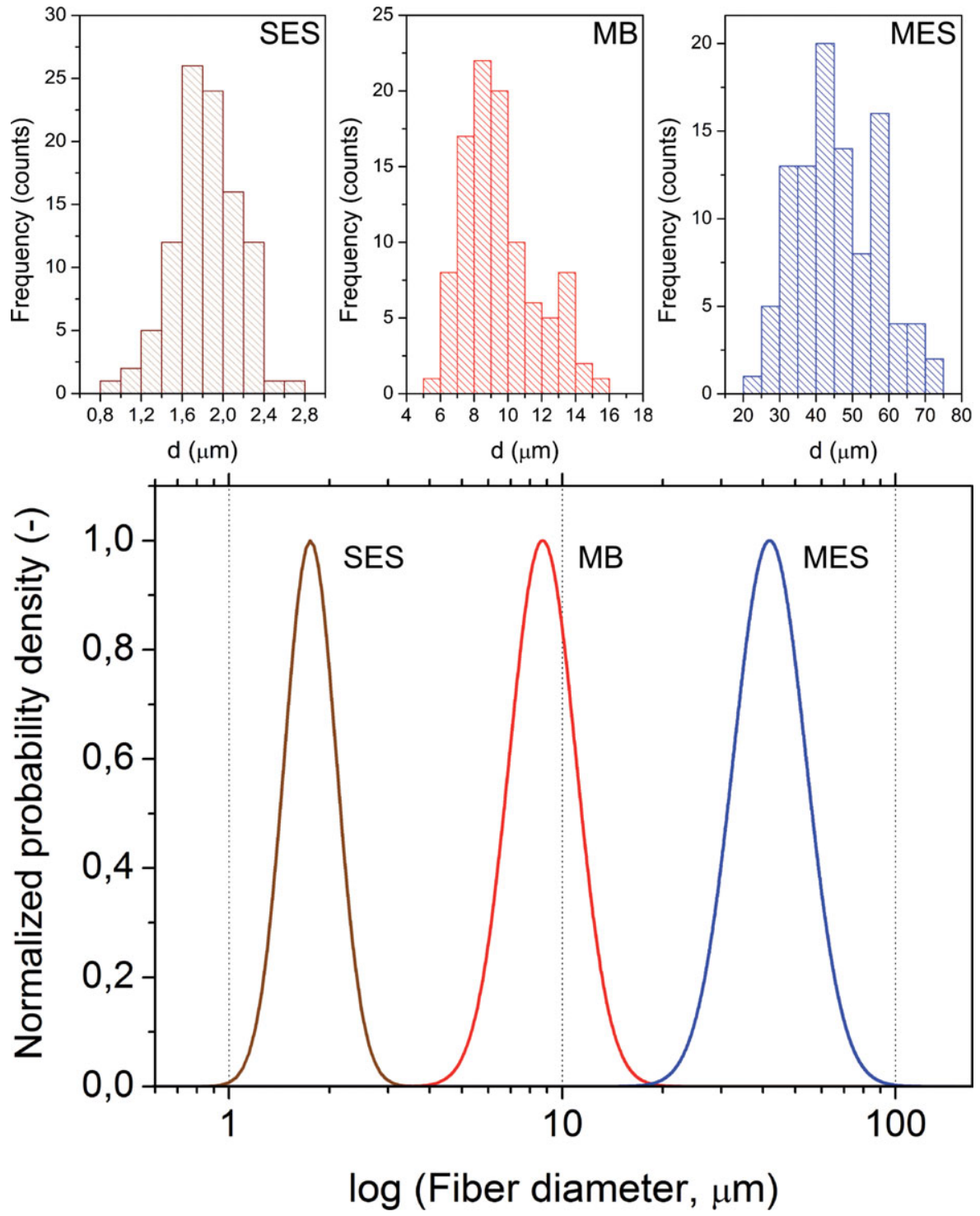

Figure 5. Normalized lognormal distribution fits to logarithmic diameter for PVPA64-based fibrous samples containing $10 \%$ CAR and $15 \%$ PEG 3000, prepared by SES, MB, and MES, and histograms of the measured diameters $(n=100)$.

The thermograms of the common composition processed by three different fiber formation techniques and melt extrusion did not show the melting peak of CAR; the drug turned into an amorphous form in each case. The applied techniques have different drug amorphization mechanisms. SES can gently turn the API into an amorphous form by the ultrafast evaporation of the solvent. The high shear forces during extruded and the elevated temperatures followed by a quick cooling, especially at MES and MB, are also in favor of drug amorphization.

The crystalline behavior of PEG could not be fully terminated by the amorphization forces described above. Besides the distributed part of PEG, small segments of PEG chains could organize during solidification in a folded state. Those ordered PEG segments provided rigidity to the dispersions leading to better processibility (grindability). The melting of the ordered PEG segments can be used to draw conclusions from the dispersions. The solvent-based electrospun sample had the highest PEG melting temperature $\left(59^{\circ} \mathrm{C}\right)$ and the raw-extruded material had the lowest $\left(52^{\circ} \mathrm{C}\right)$. During solution electrospinning, the solidification of the PEG content may have an increased rate as DCM, in that case the only compatible solvent with PEG, evaporates quickly, leading to somewhat better organized PEG chains of higher melting temperature. In turn, the viscous melt, the intense mixing and the fast cooling during the extrusion process kept the well-distributed PEG chains in contact with larger amount of other components, that is, a lowered melting point could be observed. Melt extrusion also served the input material for MES and MB, but during the heating period without mixing some relaxation could occur within the PEG phase, similarly elevated melting points could be measured $\left(58^{\circ} \mathrm{C}\right)$.

\section{X-ray Diffraction}

X-ray diffraction was used to analyze the prepared solid dispersions in regard of crystallinity of the drug and the applied excipients the result of which is shown in Figure 7.

The physical mixture of 5\% crystalline CAR and PVPVA64 served as a reference; the sharp and most intense diffraction peaks of CAR were still detectable emerging from the 


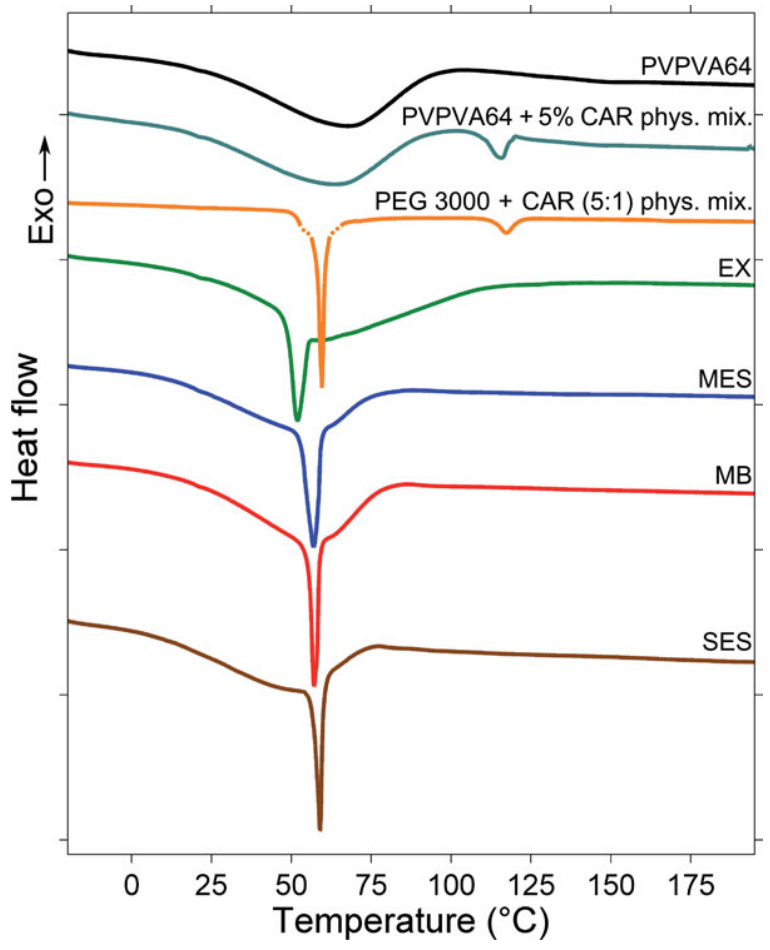

Figure 6. Differential scanning calorimetry thermograms of the pure PVPVA64, physical mixture of PVPVA64, and 5\% CAR, physical mixture of PEG 3000 and CAR (5:1), and the extruded, MES, MB, and SES samples containing similarly $10 \%$ CAR and 15\% PEG 3000.

amorphous background of PVPVA64. The diffraction pattern of PEG 3000 showed two main peaks at $2 \theta=19.3^{\circ}$ and $23.5^{\circ}$. The solid dispersions prepared by different techniques did not show any sign of crystallinity regarding the drug compound confirming the amorphous state of CAR also confirmed by DSC. However, the crystallinity of the PEG content appeared to be not so intense in the X-ray diffractograms of the samples in contrast to the DSC results evidencing the presence of small ordered PEG segments. Only weak humps were observable, stemming from the aforementioned main peaks of PEG 3000 with slight differences between the extrudate and the fibers.

\section{RP-HPLC Studies}

Reversed-phase high-performance liquid chromatography coupled with UV detection was applied to determine the amount of the degradation products of CAR in the prepared solid dispersions. As a starting point, the current ICH guideline of impurities in new drug products describes the relevant limits of the degradation products. ${ }^{48}$ The absolute maximum dose of CAR is $2 \times 50 \mathrm{mg}$ daily ${ }^{49}$ thus the limits for each degradation products are as follows: reporting threshold-above $0.1 \%$; identification threshold-above 0.2\%; qualification threshold-above $200 \mu \mathrm{g}$ (in this case it equals to $0.2 \%$ as well). In contrast, the European Pharmacopoeia (Ph. Eur.) specifies a total impurity threshold of $0.5 \%$ in products containing CAR. ${ }^{50}$

Despite that CAR can be labeled as a thermosensitive compound when it is amorphized, ${ }^{32}$ solid dispersions of high purity could be prepared even after using different melting methods. According to the impurity tests, crystalline CAR contained small amounts of impurities $(0.07 \pm 0.01 \%)$. Turning CAR into an amorphous form using the gentle SES had practically no effect on the purity of the formulation $(0.08 \pm 0.01 \%)$. In turn, the applied melting methods increased noticeably the amount of the degradation products. The melt-extrusion step led to a $0.18 \pm 0.02 \%$ total impurity, whereas further processing into melt electrospun and melt-blown fibers also had an additional thermal impact resulting in a $0.24 \pm 0.02 \%$ (MES) and 0.27 $\pm 0.02 \%$ (MB) total impurity. Thus, none of the prepared solid dispersions exceeded the total impurity threshold of $\mathrm{Ph}$. Eur. and there were no individual degradation products beyond the ICH identification threshold $(0.2 \%)$ based on the recorded chromatograms.

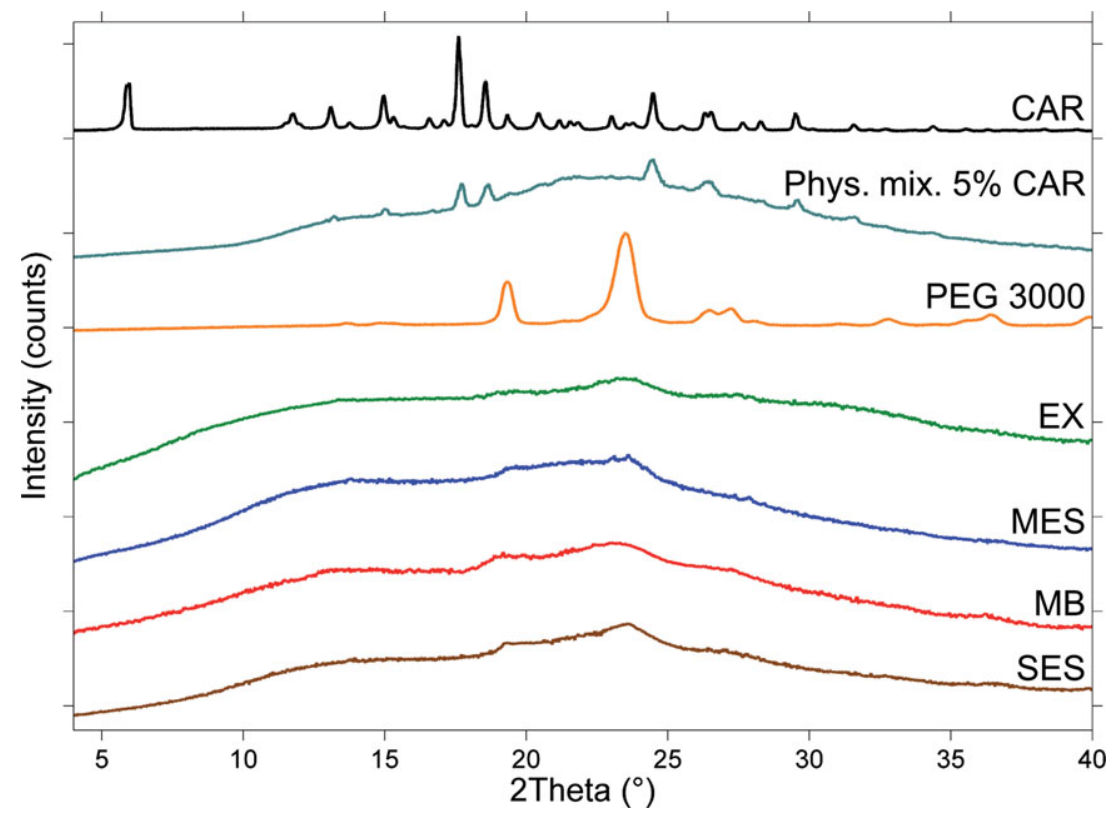

Figure 7. X-ray diffraction patterns of crystalline CAR, physical mixture of PVPVA64 and 5\% CAR, PEG 3000, and the extruded, MES, MB, and SES samples containing similarly $10 \%$ CAR and 15\% PEG 3000. 
Although fiber formation from melt (MES, MB) had a significant additional degrading effect, it must be noted that by direct fiber formation through an optimized high-throughput spinneret the level of the concerned extra contamination can be much less. Note that the chromatography measurements did not reveal any newly eluted peak when comparing EX, MES, and MB. During MB, despite the intense biphasic exposure (molten polymer and hot air), the polymeric matrix seems to have a protective effect on the API from the oxidative stress (considering that CAR is mildly prone to degradation in a peroxidic medium ${ }^{51}$ ).

\section{In Vitro Dissolution}

The enhanced drug release properties of the fibrous samples and the ground extrudate were analyzed compared with the poorly soluble crystalline API (Fig. 8).

Carvedilol is a weak-basic compound having a limited solubility at both acidic and especially neutral $\mathrm{pH}$ values; thus, an increased dissolution rate is a rather challenging formulation task when tests are carried out in a $\mathrm{pH} 6.8$ medium. Despite this, the prepared PVPVA64-based solid dispersions with 10\% CAR and 15\% PEG 3000 exhibited ultrafast drug dissolution. In contrast to that, only $10 \%$ of the crystalline CAR with particles of 10-50 $\mu \mathrm{m}$ size range (Fig. 4a) was dissolved after $20 \mathrm{~min}$ and $20 \%$ after $1 \mathrm{~h}$. In accordance to the NoyesWhitney equation, the fastest dissolution speeds belong to the fibrous samples with large specific surface areas, in these cases less than 5 min were needed for total drug release. However, the SES sample with the smallest average fiber diameter and thus the largest surface area showed a somewhat moderate dissolution compared with MB and MES. The reason for this seemingly unexpected phenomenon lies in the different accessibility of the fibers by the dissolution media. ${ }^{14}$ The MES and MB fibers could be collected loosely, that is, with high porosity, whereas SES generated a thick fibrous mat with tightly packed fibers, thus the huge surface area could not be fully exploited during the dissolution process. Although MES and MB fibers also had a fivefold ratio in the specific surface area

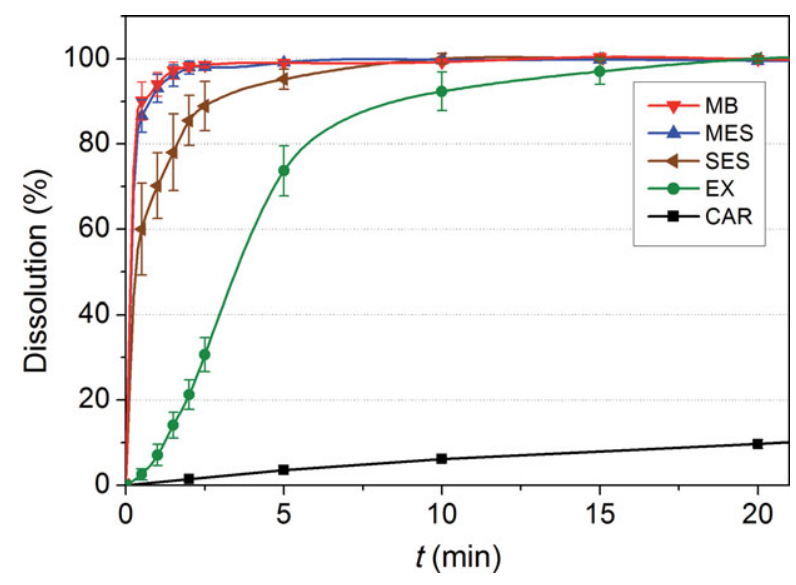

Figure 8. Dissolution profiles of CAR $[12.5 \mathrm{mg}$ dosage, $900 \mathrm{~mL} \mathrm{pH}$ 6.8, USP Dissolution Apparatus 2 (paddle), 100 rpm, $37^{\circ} \mathrm{C}$ ]. PVPVA64based extruded, MES, MB, and SES samples containing similarly $10 \%$ CAR and 15\% PEG 3000; unprocessed crystalline CAR. The error bars indicate the standard deviations $(n=3)$. in favor of $\mathrm{MB}$, the dissolution characteristics were similar, which can be attributed to the somewhat limited distribution of the cotton-wool-like MB samples in the dissolution vessel, as opposed to the thicker and more brittle MES fibers. The ground extrudate showed significantly slower dissolution in contrast to the fibrous samples owing to the larger particle sizes, whereas the almost total drug release could be measured after $15 \mathrm{~min}$. The results confirm the great efficiency of the combination of polymer-based solid dispersions with an increased specific surface area, and also imply the importance of understanding the effect of the wetting characteristics (e.g., the porosity as a result of the macroscopic structure of the mat) of drug-loaded fibrous materials on the dissolution behavior.

\section{CONCLUSIONS}

Three different fiber formation techniques, SES, MES, and MB, were used to prepare PVPVA64-based fast-dissolving mats to enhance the dissolution characteristics of the poorly watersoluble CAR. Viscosity was found to be a key condition to produce melt electrospun fibers; thus, the final common composition used for comparison was optimized based on oscillatory viscosimetry; $15 \%$ PEG 3000 had appropriate plasticizing effect in the presence of $10 \%$ API. MB was successfully performed under the same thermal and feeding circumstances as MES but using a high-speed air stream. The SEM images coupled with fiber diameter analysis revealed well-separated diameter distributions; the average diameters increased toward solventbased electrospun $<$ melt-blown $<$ melt electrospun fibers. DSC and XRD did not show any crystallinity belonging to CAR in the extruded and fibrous samples. Purity measurements showed an acceptable impurity content in the samples prepared by melting methods including MB, whereas SES had practically no degrading effect. Fast drug release of the weak-base CAR could be measured at neutral $\mathrm{pH}$ in the case of the fibers; significant improvement could be achieved compared with the crystalline API. Further steps to obtain typical solid dosage forms (e.g., compressed tablets) using the PVPVA64+PEG3000-based solid dispersions is facilitated by the good processibility (grindability) of the rigid solid dispersion and the subsequent mixing with other excipients.

The results demonstrate that the industrially available MB is a promising technique to produce drug-loaded polymeric mats with modified drug release properties. Further investigations are required to test the processibility of other pharmaceutically applicable polymers via MB. Inertisation of the blowing process can be also a relevant technology issue when the API is highly sensitive to an oxidative stress.

\section{ACKNOWLEDGMENTS}

We are grateful to Dénes Varga, Hajnalka Pataki, and Metalweld Kft. for their technical support. This project was supported by the New Széchenyi Plan (project ID: TÁMOP-4.2.1/ B-09/1/KMR-2010-0002), OTKA grants PD-108975 and 112644, and the János Bolyai Research Scholarship of the Hungarian Academy of Sciences. 


\section{REFERENCES}

1. Nagy ZK, Balogh A, Vajna B, Farkas A, Patyi G, Kramarics Á, Marosi G. 2011. Comparison of electrospun and extruded Soluplus ${ }^{\circledR}$-based solid dosage forms of improved dissolution. J Pharm Sci 101:322-332. 2. Verreck G, Chun I, Peeters J, Rosenblatt J, Brewster ME. 2003. Preparation and characterization of nanofibers containing amorphous drug dispersions generated by electrostatic spinning. Pharm Res 20:810-817.

3. Yu DG, Xu Y, Li Z, Du LP, Zhao BG, Wang X. 2014. Coaxial electrospinning with mixed solvents: From flat to round Eudragit L100 nanofibers for better colon-targeted sustained drug release profiles. J Nanomater. http://www.hindawi.com/journals/jnm/2014/967295/abs/.

4. Nagy ZK, Nyúl K, Wagner I, Molnár K, Marosi G. 2010. Electrospun water soluble polymer mat for ultrafast release of Donepezil HCl. Express Polym Lett 4:763-772.

5. Vrbata P, Berka P, Stránská D, Doležal P, Musilová M, Čižinská L. 2013. Electrospun drug loaded membranes for sublingual administration of sumatriptan and naproxen. Int J Pharm 457:168-176.

6. Kaassis AYA, Young N, Sano N, Merchant HA, Yu DG, Chatterton NP, Williams GR. 2014. Pulsatile drug release from electrospun poly(ethylene oxide)-sodium alginate blend nanofibres. J Mater Chem B 2:1400-1407.

7. Nagy ZK, Wagner I, Suhajda A, Tobak T, Harasztos AH, Vigh T, Soti PL, Pataki H, Molnar K, Marosi G. 2014. Nanofibrous solid dosage form of living bacteria prepared by electrospinning. Express Polym Lett 8:352-361.

8. Keseru GM, Makara GM. 2009. The influence of lead discovery strategies on the properties of drug candidates. Nat Rev Drug Discov 8:203-212.

9. Lipinski CA. 2000. Drug-like properties and the causes of poor solubility and poor permeability. J Pharmacol Toxicol 44:235-249.

10. Sastry SV, Nyshadham JR, Fix JA. 2000. Recent technological advances in oral drug delivery-A review. Pharm Sci Technol 3:138-145. 11. Langer R. 1993. Polymer-controlled drug delivery systems. Accounts Chem Res 26:537-542.

12. Noyes AA, Whitney WR. 1897. The rate of solution of solid substances in their own solutions. J Am Chem Soc 19:930-934.

13. Liu YY, Li QW, Hu QX, Jing CJ, Wang QG. 2011. A new spurts controllable electrospinning collecting device designed basing on advanced motion control. Appl Mech Mater 44-47:1698-1702.

14. Nagy ZK, Balogh A, Drávavölgyi G, Ferguson J, Pataki H, Vajna B, Marosi G. 2012. Solvent-free melt electrospinning for preparation of fast dissolving drug delivery system and comparison with solventbased electrospun and melt extruded systems. J Pharm Sci 102:508517.

15. Patyi G, Bodis A, Antal I, Vajna B, Nagy ZK, Marosi G. 2012. Thermal and spectroscopic analysis of inclusion complex of spironolactone prepared by evaporation and hot melt methods. J Therm Anal Calorim 102:349-355.

16. Sauceau M, Fages J, Common A, Nikitine C, Rodier E. 2010. New challenges in polymer foaming: A review of extrusion processes assisted by supercritical carbon dioxide. Prog Polym Sci 36:749-766.

17. Grohganz H, Priemel PA, Löbmann K, Nielsen LH, Laitinen R, Mullertz A, Mooter GV, Rades T. 2014. Refining stability and dissolution rate of amorphous drug formulations. Expert Opin Drug Deliv 11:977-989.

18. Nagy ZK, Sauceau M, Nyúl K, Rodier E, Vajna B, Marosi G, Fages J. 2012. Use of supercritical $\mathrm{CO}_{2}$-aided and conventional melt extrusion for enhancing the dissolution rate of an active pharmaceutical ingredient. Polym Advan Technol 23:909-918.

19. Moulton SE, Wallace GG. 2014. 3-dimensional (3D) fabricated polymer based drug delivery systems. J Control Release 193:2734.

20. Maniruzzaman M, Boateng JS, Snowden MJ, Douroumis D. 2012. A review of Hot-melt extrusion: Process technology to pharmaceutical products. ISRN Pharm. http://www.hindawi.com/ journals/isrn/2012/436763/abs/.
21. Foster A, Hempenstall J, Tucker I, Rades T. 2001. Selection of excipients for melt extrusion with two poorly water-soluble drugs by solubility parameter calculation and thermal analysis. Int J Pharm 226:147-161.

22. Li HY, Bubakir MM, Xia T, Zhong XF, Ding YM, Yang WM. 2014. Mass production of ultra-fine fibre by melt electrospinning method using umbellate spinneret. Mater Res Innov 18(S4):921-925.

23. Wang Q, Curtis CK, Thoppey NM, Bochinski JR, Gorga RE, Clarke LI. 2014. Unconfined, melt edge electrospinning from multiple, spontaneous, self-organized polymer jets. Mater Res Exp 1:045304.

24. Petrik S, Maly M. 2009. Production nozzle less electrospinning nanofiber technology. Mat Res S 1240:7-18.

25. Persano L, Camposeo A, Tekmen C, Pisignano D. 2013. Industrial upscaling of electrospinning and applications of polymer nanofibers: A review. Macromol Mat Eng 298:504-520.

26. Nagy ZK, Balogh A, Démuth B, Pataki H, Vigh T, Szabó B, Molnár K, Schmidt BT, Horák P, Marosi G, Verreck G, Van Assche I, Brewster ME. 2015. High speed electrospinning for scaled-up production of amorphous solid dispersion of itraconazole. Int J Pharm 480:137-142.

27. Luo CJ, Stoyanov SD, Stride E, Pelan E, Edirisinghe M. 2012. Electrospinning versus fibre production methods: From specifics to technological convergence. Chem Soc Rev 41:4708-4735.

28. Hutmacher DW, Dalton PD. 2011. Melt electrospinning. Chem Asian J 6(1):44-56.

29. Bresse RR, Ko WC. 2003. Fiber formation during melt blowing. Int Nonwowens J Summer 2003:21-28.

30. Shaumbaugh RL. 1988. A macroscopic view of the melt-blowing process for producing microfibers. Ind Eng Chem Res 27:23632372 .

31. Ellison CJ, Phatak A, Giles DW, Macosko CW, Bates FS. 2007. Melt blown nanofibers: Fiber diameter distributions and onset of fiber breakup. Polymer 48:3306-3316.

32. Balogh A, Drávavölgyi G, Faragó K, Farkas A, Vigh T, Sóti PL, Wagner I, Madarász J, Pataki H, Marosi G, Nagy ZK. 2014. Plasticized drug-loaded melt electrospun polymer mats: Characterization, thermal degradation and release kinetics. J Pharm Sci 103(4):12781287.

33. Loftsson T, Vogensen SB, Desbos C, Jansook P. 2008. Carvedilol: Solubilization and cyclodextrin complexation: A technical note. AAPS Pharm Sci Tech 9(2):425-430.

34. Sugawara M, Kadomura S, He X, Takekuma Y, Kohri N, Miyazaki K. 2005. The use of an in vitro dissolution and absorption system to evaluate oral absorption of two weak bases in $\mathrm{pH}$-independent controlled-release formulations. Eur J Pharm Sci 26:1-8.

35. Fordtran JS, Walsh JH. 1973. Gastric acid secretion rate and buffer content of the stomach after eating. J Clin Invest 52:645-657.

36. Davis ME, Brewster ME. 2004. Cyclodextrin-based pharmaceutics: Past, present and future. Nat Rev Drug Discov 3:10231035 .

37. Deering TB, Malagelada JR. 1977. Comparison of an H2 receptor antagonist and a neutralizing antacid on postprandial acid delivery into the duodenum in patients with duodenal ulcer. Gastroenterology 73:11-14.

38. Deering TB, Carlson GL, Malagelada UR, Duenes HA, McCall JT. 1979. Fate of oral neutralizing antacid and its effect on postprandial gastric secretion and emptying. Gastroenterology 77:986-990.

39. Weitschies W, Kosch O, Mönnikes H, Trahms L. 2005. Magnetic marker monitoring: An application of biomagnetic measurement instrumentation and principles for the determination of the gastrointestinal behavior of magnetically marked solid dosage forms. Adv Drug Deliv Rev 57:1210-1222.

40. Rathore MM. 2010. Thermal engineering. New Delhi, India: Tata McGraw Hill, pp 298-331.

41. Stojanović J, Vladimirovm S, Marinković V, Veličković D, Sibinović P. 2007. Monitoring of the photochemical stability of carvedilol and its degradation product by the RP-HPLC method. J Serb Chem Soc 72:37-44. 
42. Janssens S, Nagels S, Armas HN, D'Autry W, Schepdael AV, Mooter GV. 2007. Formulation and characterization of ternary solid dispersions made up of itraconazole and two excipients, TPGS and PVPVA 64 , that were selected based on a supersaturation screening study. Eur J Pharm Biopharm 69(1):158-166.

43. Drooge DJ, Hinrichs WLJ, Visser MR, Frijlink HW. 2006. Characterization of the molecular distribution of drugs in glassy solid dispersions at the nano-meters scale, using differential scanning calorimetry and gravimetric water vapour sorption techniques. Int J Pharm 310:220-229.

44. Zhou H, Green TB, Joo YL. 2006. The thermal effects on electrospinning of polylactic acid melts. Polymer 8:7497-7505.

45. Gu SY, Ren J, Wu QL. 2005. Preparation and structures of electrospun PAN nanofibers as a precursor of carbon nanofibers. Synthetic Met 155:157-161.
46. Hassan MA, Yeom BY, Wilkie A, Pourdeyhimi B, Khan SA. 2013. Fabrication of nanofiber meltblown membranes and their filtration properties. J Membr Sci 427:336-344.

47. Pielichowski K, Flejtuch K. 2002. Differential scanning calorymetry studies on poly(ethylene glycol) with different molecular weights for thermal energy storage materials. Polym Adv Technol 13:690-696.

48. International conference on harmonisation. 2006. Note for guidance on impurities in new drug products.

49. Rickli H, Steiner S, Müller K, Hess OM. 2003. Betablockers in heart failure: Carvedilol safety assessment (CASA 2-trial). Eur J Heart Fail 6:761-768.

50. Pharmacopoea Europaea 7.0, pp 1595-1596.

51. Lanzanova FA, Argenta D, Arend MZ, Junior LB, Cardoso SG. 2009. LC and LC-MS evaluation of stress degradation behavior of carvedilol. J Liq Chromatogr R T 32(4):526-543. 